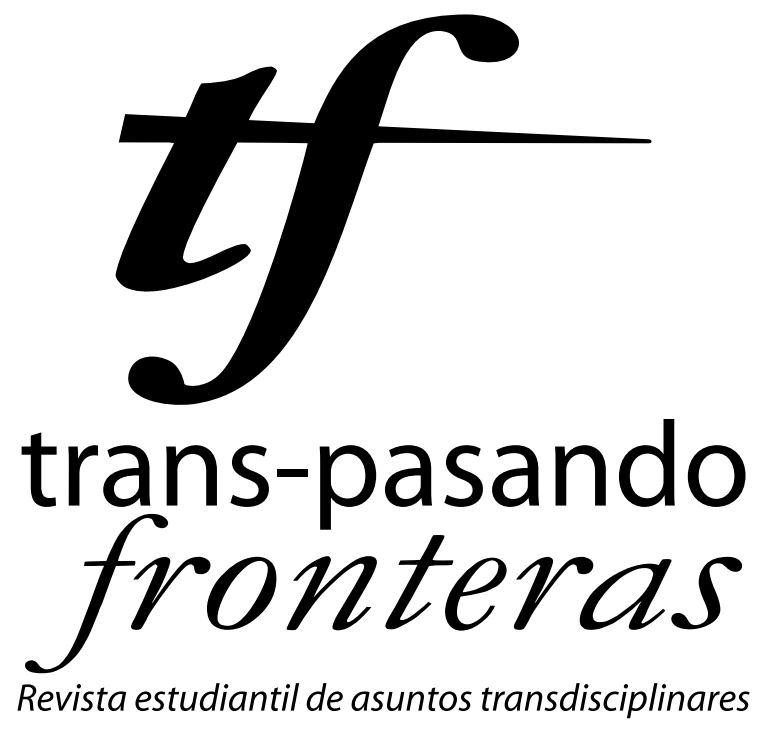

Una publicación de

Estudios

Interdisciplinarios

Jurídicos, Sociales

000 y Humanistas

ICESS

FACULTAD DE

DERECHO Y CIENCIAS

SOCIALES

然 UNIVERSIDAD 


\title{
Lecciones del Archipiélago Gulag
}

\author{
Carlos Bello Gándara \\ (carlosjobello@hotmail.com) \\ Andrés F. Vásquez \\ (andres.vasquez1@correo.icesi.edu.co)
}

SOLZHENITSYN, Aleksandr (2007). El Archipiélago Gulag (Josep M. Güel y Enrique Fernández Vemet, trad.). Edición electrónica.

A lo largo de la historia de la humanidad han existido regímenes instaurados inicialmente como una respuesta frente a problemáticas originadas por una profunda desigualdad entre clases sociales, pero que una vez en el poder dichos gobernantes se tornan totalitarios y represivos. Tal fue el caso de la Unión Soviética, en la cual se estableció un régimen comunista como resultado de la revolución contra una monarquía incapaz resolver las necesidades del pueblo, pero este nuevo gobierno empleó la violencia y la represión contra sus disidentes para garantizar su continuidad, por lo que millones de personas tuvieron que vivir trabajos forzados y las desapariciones de familiares.
Naturalmente, la represión también viene acompañada de la censura informativa. Las autoridades llevaban a cabo acciones con el fin de evitar la publicación de obras que estuvieran en contra de su ideología política o que divulgaran los atropellos que se cometían, por lo que todos los medios de comunicación estaban controlados y los autores debían pertenecer a una asociación avalada por el gobierno. Sin embargo, a través de algunos escritores rusos que se arriesgaron a plasmar en sus obras la realidad imperante, se logró crear un registro histórico que en la actualidad permite conocer algunos de los sucesos nombrados anteriormente. Uno de estos escritores fue 
Aleksandr Solzhenitsyn, autor del "Archipiélago Gulag”, una obra donde a partir de entrevistas realizadas a 227 personas sobrevivientes de los campos de trabajo forzado y su propia experiencia en estos, une las piezas del rompecabezas para mostrar un panorama acerca del “Gulag”, las detenciones injustificadas y el miedo reinante en la sociedad soviética de la época estalinista. Por dichas razones esta obra nunca llega a ser publicada dentro de la URSS de manera oficial y solo llega a esta a través del samizdat. Teniendo en cuenta lo anterior, y considerando que Solzhenitsin afirmó una vez que "la literatura se convierte en la memoria viva de una nación”, se llega a la siguiente pregunta: ¿Cuáles son las lecciones que se pueden derivar del “Archipiélago Gulag” para la sociedad moderna?

Es imperativo describir brevemente el contexto político en el que se desarrolla el texto de Solzhenitsyn para entender el alcance de su obra. En 1922, Iósif Stalin se convierte en el secretario general del partido comunista y a finales de la década de los 20's asume el poder en toda la Unión Soviética, este controvertido personaje de la historia rusa gobernaría hasta su muerte en 1953. Pre- cisamente lo narrado en el "Archipiélago Gulag" transcurre durante este tiempo en el cual Stalin gobierna con mano dura ya que empieza a controlar por completo la vida de la sociedad soviética con el fin de cumplir la transformación del nuevo hombre soviético y del comunismo. Con estos objetivos en mente Stalin empieza a gestionar un sistema jurídico diseñado para separar a los antisoviéticos de la sociedad. Esto desemboca finalmente en el “Gulag” descrito en el libro, un sistema de campos de concentración para trabajos forzados diseminados por todo el país.

Una las lecciones apreciables del libro proviene de la descripción de los arrestos llevados a cabo por las autoridades. Cualquier persona podía ser arrestada sin motivo aparente, en sin importar la hora o el lugar, por lo que gran parte de la sociedad vivía con la preocupación constante de que podían ser detenidos y presenciando como personas cercanas desaparecían repentinamente. Solzhenitsyn resumen en su libro aquella situación de esta forma: "En una palabra, «vivimos en unas condiciones tan atroces que un hombre desaparece sin dejar rastro, y sus personas más allegadas, su madre, su esposa..., pasan años 
sin saber qué ha sido de éll)" (Solzhenitsyn, 2007: 12). Sin embargo, este tipo de atropellos contra la población civil solo profundizaría la crisis del régimen soviético a largo plazo, demostrando que un sistema basado en infundir temor es completamente inviable.

Ahora se puede introducir uno de aspectos más importantes del proceso de condena a las víctimas, el cual es el sistema judicial. Los encargados de llevar a cabo el proceso judicial eran los ribetes azules o jueces de sumario, quienes en lugar de llegar a la verdad solo buscaban aumentar la cifra de condenados a trabajos forzados, incluso aplicando todo tipo de torturas para que las víctimas confesaran crímenes que no habían cometido. La razón de tras de esto se describe en el texto de Solzhenitsyn: "Pues porque así era más cómodo, porque así no ibas a contracorriente de todos los demás. Porque estas cifras significaban una vida apacible, pagas extras, condecoraciones y ascensos, así como el crecimiento y prosperidad de los propios Órganos" (Solzhenitsyn, 2007: 84). Con lo anterior se puede observar que realmente la justicia en la Unión Soviética era ineficaz al momento de brindar justicia a los acusados de antisoviéticos ya que siempre los declaraba culpables, pues el hecho era que para Stalin era imposible imaginar que no hubiera algún enemigo en toda la Unión Soviética. Lo que hizo que la justicia se volviera en contra de la sociedad, volviéndose en el proceso ineficaz, lo cual tal vez no dista mucha de la justicia en la Federación Rusa en donde también se empieza a observar similitudes la mencionada anteriormente, una de estas tienen que ver con el que se estén enjuiciando a personas que están en contra de Vladimir Putin.

Otra de las lecciones procede de las condiciones de vida una vez la persona ingresa en el sistema carcelario. Los prisioneros carecían de muchas garantías básicas para vivir dignamente y a la mayoría se le asignaban los llamados trabajos comunes, que son las labores físicas más duras como la extracción de oro, la construcción de minas, tala de bosques, entre otras. Dichas condiciones se pueden evidenciar en el libro cuando el autor plantea que las víctimas frecuentemente eran intimidadas cuando los jueces les decían: "De mí depende a qué campo vas a ir. Hay campos de campos. Ahora, hasta tenemos trabajos forzados. Si eras sincero te pondremos en un sitio suave; si te obstinas, veinticinco años trabajando 
bajo tierra y con grilletes" (Solzhenitsyn, 2007: 63). Ciertamente en Rusia ya no se aplican trabajos forzados en las penitenciarías, pero las condiciones actuales de encarcelamiento todavía carecen de elementos básicos, situación que se presenta en gran parte de las prisiones. Según los datos publicados por el Fiscal General de Rusia, en el año 2012 murieron 3907 personas en las cárceles rusas y se detectaron más de 43.000 irregularidades en referencia a las condiciones de encarcelamiento de los reclusos. Sin embargo, es importante resaltar que el gobierno ruso está intentado reformar el actual sistema de colonias penitenciarias con medidas similares a los estándares europeos y planes para reducir la reincidencia, todo con el fin de dejar atrás la herencia del Gulag.

Un aspecto interesante es que Solzhenitsyn no fue el único escritor en abordar la temática del Gulag, algo comprensible dada la trascendencia de esta problemática en la vida de millones personas que también sufrieron la privación de su libertad o de sus familiares. Cabe resaltar el caso de Varlam Shalámov, que estuvo durante diecisiete años en los campos de trabajos forzados. El carácter reflejado en sus escritos tenía una con- tundencia similar a la implementada por Solzhenitsin, pero no logró mucho reconocimiento en Rusia ni en el extranjero. Varlam Shalámov no aceptó una propuesta de Solzhenitsin para ser coautor del "Archipiélago Gulag" porque no compartía la intencionalidad histórica de la obra. Shalámov escribió su propia obra titulada "Cuentos de Kolymá" donde narra la vida en el campo de trabajo forzado, pero muestra su visión filosófica ya que el libro se afirma que "el ser humano sobrevive gracias a la habilidad que tiene de olvidar, porque la memoria siempre está dispuesta a descartar lo negativo y a retener solo los recuerdos positivos".

En conclusión, el "Archipiélago Gulag" es una obra que no ha perdido vigencia y que representa un registro histórico, al no permitir que hechos trágicos del pasado caigan en el olvido. Por esta razón, la importancia de la obra radica en mostrar a las nuevas generaciones los sucesos ocurridos, para así evitar cometer los mismos errores y aprender lecciones que proyecten un mejor futuro.

\section{Referencias}

SOLZHENITSYN, Aleksandr (2007). El Archipiélago Gulag (Josep M. Güel y 
Enrique Fernández Vemet, trad.). [Obra original publicada en 1973]. Edición electrónica

ZAGVÓZDINA, Daria. La cárcel rusa trata de liberarse de la herencia del Gulag. Rusia Hoy. Consulta realizada el 2 de mayo de 2013, desde: http://rusiahoy.com/sociedad/2013/05/02/la_carcel_rusa_trata_de_liberarse_de_la_herencia_del_gulag_27477.html

BUTCHARD, George. "El gulag desde dentro". En: Rusia Hoy. Consulta realizada el 16 de julio de 2012, desde: http://rusiahoy.com/articles/2012/07/16/ el_gulag_desde_dentro_17985.html

RUSIA HOY (2013). El libro que descubrió al mundo el gulag conserva su vigor a los 50 años. Noticias. Consulta realizada el 5 de enero de 2013, desde: http://rusiahoy.com/articles/2013/01/05/ el_libro_que_descubrio_al_mundo_el_gulag_conserva_su_vigor_a los_50_23705.html 